\title{
Spatial and temporal expressions of prune reveal a role in Müller gliogenesis during Xenopus retinal development
}

\author{
Aikaterini Bilitou ${ }^{\mathrm{a}, 1}$, Nadia De Marco ${ }^{\mathrm{b}, 1}$, Anna Maria Bello ${ }^{\mathrm{c}, 1}$, Livia Garzia ${ }^{\mathrm{c}}$, Pietro Carotenuto ${ }^{\mathrm{c}}$, \\ Michelle Kim ${ }^{\text {a }}$, Chiara Campanella ${ }^{\mathrm{b}}$, Shin-ichi Ohnuma ${ }^{\mathrm{a}, *}$, Massimo Zollo ${ }^{\mathrm{c}, \mathrm{d}, * *}$ \\ a UCL Institute of Ophthalmology, University College London, 11-43 Bath Street, London EC1V 9EL, UK \\ b Department of Structural and Functional Biology, University of Naples Federico II, Naples, Italy \\ c CEINGE - Biotecnologie Avanzate s.c. a r.l., Via Gaetano Salvatore, 486, 80145, Naples, Italy \\ ${ }^{\mathrm{d}}$ Dipartimento di Biochimica e Biotecnologie Mediche, University of Naples Federico II, Naples, Italy
}

\section{A R T I C L E I N F O}

\section{Article history:}

Accepted 2 August 2012

Available online 15 August 2012

\section{Keywords:}

Retina

Xenopus

Prune

PDE

Müller glia

\begin{abstract}
A B S T R A C T
The development of stratified retinal cell architecture is highly conserved in all vertebrates, implying that a common fundamental molecular mechanism is involved in the generation of the organized retina. However, the detailed molecular mechanisms of retinal development are not fully understood. Here we have identified the Xenopus ortholog of prune and show that it is expressed in both differentiating and differentiated retinal domains during development. Interestingly, these spatial and temporal expression patterns coincide with the expression of prune binding partners, the NM23 family members. Overexpression of prune in retinal precursor cells significantly increases the ratio of Müller glial cells as observed by modulation of NM23 activity (Mochizuki et al., 2009). However, a mutated form of prune that has replacement of four aspartate (D) residues (D'Angelo et al., 2004), essential for phosphodiesterase activity, does not exhibit gliogenic activity. Our observations suggest that Xenopus prune may regulate Müller gliogenesis through phosphodiesterasemediated regulation of NM23 family members.
\end{abstract}

(c) 2012 Elsevier B.V. All rights reserved.

\section{Introduction}

The mature neural retina consists of six major classes of neurons: photoreceptors, horizontal cells, amacrine cells, interplexiform cells, bipolar cells, retinal ganglion cells and a single type of glial cells: Müller glial cells. These neurons are segregated into three cellular layers: the ganglion cell layer (GCL) contains ganglion cells, the inner nuclear layer (INL) contains bipolar, horizontal and amacrine interneurons, and the outer nuclear layer (ONL) contains rod and cone photoreceptors. The Müller glial cells are located in the INL and extend processes from the outer limiting

Abbreviations: GCL, ganglion cell layer; INL, inner nuclear layer; ONL, outer nuclear layer; CMZ, ciliary marginal zone; kDa, kilodalton; RPE, retinal pigment epithelium; OS, optic stalk; NR, neural retina; RGC, retinal ganglion cell; IPL, inner plexiform layer; MBS, modified Barth's saline; PBS, Phosphate buffered saline; hr, hour; RT, room temperature; bp, base pair; kb, kilobase; hpf, Hour post fertilization; FBS, foetal bovine serum; BSA, Bovine serum albumin; DTT, Dithiothreitol; NaF, Sodium Fluoride; $\mathrm{NaVO}_{3}$, Sodium metavanadate; MeOH, Methanol; MEMFA, MOPS/EGTA/Magnesium Sulfate/Formaldehyde Buffer; MEM, MOPS/EGTA/Magnesium Sulfate Buffer; SSC, saline-sodium citrate; TEA, Triethanolamine; MAB, 0.1 M Maleic acid, $0.15 \mathrm{M} \mathrm{Nacl}$, pH 7.5; AP, alkaline phosphatase; PH, Photoreceptor cells; HOR, Horizontal cells; BP, Bipolar cells; ML, Müller glia cells; AM, Amacrine cells; GC, Ganglion cells.

* Corresponding author.

** Correspondence to: M. Zollo, CEINGE - Biotecnologie Avanzate s.c. a r.l., Via Gaetano Salvatore, 486, 80145, Naples, Italy.

E-mail addresses: s.ohnuma@ucl.ac.uk (S. Ohnuma), massimo.zollo@unina.it (M. Zollo).

1 These authors contributed equally to the work. membrane to the inner limiting membrane. All of these retinal cell types are generated from a single sheet of neuro-epithelial cells as they differentiate in a specific temporal pattern (Ohnuma et al., 2002b). The identity of retinal neurons and glial cells is determined by the repertoire of intrinsic factors that are expressed by retinal precursor cells, as well as by extrinsic signals in the environment (Cepko et al., 1996; Edlund and Jessell, 1999; Harris, 1997). The development of this stratified retinal cell architecture is largely conserved in all vertebrates, which implies that a common fundamental mechanism is involved in the generation of these retinal cell types. Previous studies in the vertebrate retina suggest that molecules regulating cell cycle and cell differentiation/determination have an important role in retinal cell fate determination (Dyer and Cepko, 2001b; Ohnuma and Harris, 2003). For example, cyclin dependent kinase inhibitors such as p27Xic1 and p57Kip1 contribute to the cell fate determination of Müller glial cells and amacrine neurons, respectively (Daniels et al., 2004; Dyer and Cepko, 2001a; Ohnuma et al., 1999). Recently, we reported that NM23 family members directly interact with p27Xic1 and modulate p27Xic1-mediated gliogenic activity in Xenopus retina (Mochizuki et al., 2009).

Prune protein belongs to the DHH family of phosphoesterase proteins including RecJ DNA repair exonucleases, pyrophosphatases and exopolyphospatases (Aravind and Koonin, 1998) and identified from Drosophila to human (Middelhaufe et al., 2007). Studies in Drosophila showed that the genetic interaction between prune and awd (the Drosophila homolog of NM23) plays a crucial role in development 
(Timmons and Shearn, 2000). The genetic combination between these two genes was originally shown by the lethal interaction between prune and the $a w d^{K p n}$, a point mutation that corresponds to serine-97, known as the killer of prune (Kpn) (Biggs et al., 1988; Sturtevant, 1956). The interaction of prune/awd ${ }^{K p n}$ results in lethality of mutants at the second or third larval instar stage, as they acquire a melanotic phenotype in swelling cells of imaginal disc structures that do not follow normal tissue development (Orevi and Falk, 1975; Timmons and Shearn, 1996; Timmons et al., 1995). Additionally, gynandromorph mosaic experiments showed that the genetic interaction of prune $/ a w d^{K p n}$ gives rise to abnormal nervous system development, including a considerable hypertrophy of the neuroglia in the larval brain (Biggs et al., 1988; Hackstein, 1992; Orevi and Falk, 1974). Prune is required autonomously in the eye disc for the normal production of pteridine pigments through GTP cyclohydrolase activity (Beadle and Ephrussi, 1936). Thus, null mutations in the prune gene result in prune eye color due to reductions in red pigment accumulation (Teng et al., 1991; Timmons and Shearn, 1996). Recently, we explored the involvement of prune-NM23-H1 protein interaction in the nervous system development of mouse (Carotenuto et al., 2006). During mouse brain development, the two genes of prune and NM23-H1 are co-expressed early in the areas where neuronal differentiation and proliferation take place. These observations indicate that prune and NM23 family members may have a functional interaction in the regulation of neuronal development in vertebrates.

Moreover, the functional interaction between prune and NM23 family has been studied in cancer metastasis. NM23-H1, the awd human homolog, was isolated on the basis of its reduced expression in highly metastatic murine melanoma cell lines, as compared with their non-metastatic counterparts (Steeg et al., 1988). We have shown that human prune (h-prune) possesses phosphodiesterase (PDE)-cAMP activity and that this activity is enhanced through the interaction with NM23-H1, thus stimulating cellular motility and metastasis (D'Angelo et al., 2004). We have also shown that amplification of $h$-prune copy number induces cell proliferation through its cAMP-PDE activity in an established breast cancer cellular model (D'Angelo et al., 2004).

All observations suggest that prune may have a role in neuronal development through interaction with NM23 family members. This study will examine the expression pattern of prune in comparison with NM23 family members during vertebrate retinal development and its function in retinal cell fate determination using Xenopus embryos as a model system.

\section{Results}

\subsection{Identification of Xenopus prune orthologues}

In Drosophila and mammalian cell lines, prune protein regulates function of NM23-1 orthologs through their direct interaction (D'Angelo et al., 2004; Rosengard et al., 1989). We previously showed that NM23 family members are expressed in the differentiating and mature retina and they have an ability to modulate Müller gliogenesis in Xenopus (Mochizuki et al., 2009). To examine the role of prune in Xenopus retinogenesis, we have identified the Xenopus ortholog through BLAST search of the nucleotide and protein databases using the human prune sequence (gene ID: 58497, NM_021222). The deduced amino acid sequence of Xenopus prune is compared with those of Drosophila, mouse, zebrafish and human in Fig. 1A. The aspartate residues that correspond to the "signature" of the four domains, characteristic of the $\mathrm{DHH}$ phosphoesterase superfamily, are conserved across organisms (Fig. 1A), thus suggesting that the core structure is conserved in vertebrates. Previously we identified important structures for h-prune and NM23-H1 interaction (Middelhaufe et al., 2007). The C-terminal region of prune is essential for binding with NM23-H1. As indicated in Fig. 1A, the C-terminal region is highly conserved between organisms.

Vertebrates have about nine to ten members of the NM23 family. Each ortholog is highly conserved among species. Previous studies, including ours, identified all Xenopus members of the family (Bilitou et al., 2009; Kim et al., 2000; Mochizuki et al., 2009; Ouatas et al., 1997, 1998). Our previous work on the human genes showed that the h-prune-NM23-H1 interaction was impaired by mutations of NM23-H1-S125A, S120G and S122P, thus indicating that the region of NM23-H1 between S120 and S125 is important for the h-prune-NM23 interaction (Garzia et al., 2008). Phosphorylation on NM23-H1 by the casein kinase I (delta and epsilon) is a critical posttranslational modification regulating prune-NM23-H1 interaction (Garzia et al., 2008). Comparison of human NM23-H1 with Xenopus and mouse NM23 family members shows a remarkable evolutionary conservation around the region of residues S120-S125 and several casein kinase phosphorylation sites (Fig. 1B). In Fig. 1C, we show a schematic representation of h-prune and NM23 protein structures highlighting the respective regions of binding as demonstrated before (Middelhaufe et al., 2007). The C-terminal region of prune protein is essential to binding; furthermore, the h-prune-NM23 interaction was impaired by NM23-H1-S125A, and with NM23-H1-S120G and NM-23H1-S122P, thus indicating that the region of NM23 between N115 and E127 is important for the h-prune-NM23 interaction. This region is highly conserved in the NM23 proteins across other species, and we have previously showed the interaction between h-prune and NM23-X2 (Garzia et al., 2008). In this work supporting previous analyses (Garzia et al., 2008, see supplemental Fig. 2) and in other species proteins, the interaction occurring between these two proteins is corroborated additionally by interaction of Xenopus NM23-X2 isoform and X-prune-protein. These analyses were performed by immunoprecipitation analyses in human overexpressed HEK-293 cellular system (see Supplemental Fig. 1). To date we are not able to distinguish which NM23 isoforms (X1 or X2 or both) can immunoprecipitate prune in Xenopus because we cannot distinguish which of the two isoforms are directly binding to X-prune.

Taken together, these observations support that the Xenopus prune has a functional interaction with the Xenopus NM23 family members as observed in the human and fly counterparts.

\subsection{Expression analysis of Xenopus prune and its binding partner NM23 proteins}

To obtain information about the role of Xenopus prune in eye development, its temporal and spatial expression patterns have been examined by in situ hybridization and immunohistochemistry.

Figs. 2A-I show the whole-mount in situ hybridization of Xenopus embryos at different stages of development using anti-sense probes. Maternal X-prune mRNA is detected after gastrulation (Figs. 2A-B) and persists through neurulation (Fig. $2 \mathrm{C}$ ). At stage 21, the staining is observed mainly in the dorsal side of embryos including neuroectoderm (Fig. 2D). The expression in neural tissue continues through organogenesis until stage 41 (Figs. 2E-I). At around stage 32, when retinal cell fate is actively determined, we could observe strong staining in the whole retina (Fig. 2F). Then, as the retina develops, the staining in the differentiated retina is gradually reduced. At stage 35 , the staining is enriched at the peripheral retina near the lens (Fig. $2 \mathrm{H}$ ).

To examine the expression pattern of prune in more detail in the developing retina, we have performed in situ hybridization on retinal cryosections. At stage $32, X$-prune is ubiquitously detected in the retinal neuroepithelium (Fig. 3A). From stage 36 onwards, the staining persists throughout the retina but becomes more prominent at the peripheral retina (Figs. 3B-G). The stronger staining of the peripheral retina detected on the cryosections is consistent with the whole mount in situ hybridization data (Fig. 2). The Xenopus retina continuously grows during the entire life of the animal. At late stages, new cells are produced from the peripheral region of retina, the ciliary marginal zone (CMZ) (highlighted in Figs. 3D-G). The retinal stem cells are located at the most peripheral region in the $\mathrm{CMZ}$ and gradually develop all types of neurons and glial cells in the CMZ. Therefore, genes important for cell fate determination are expressed in the CMZ, while those 
A

Hs.Prune 1 . MEDY LQGCRAALQ ............ ESRP LHWLGNEAODLCS TVSALALAF YLAKT TEAEEV. FVPVLN IKRSEL 63

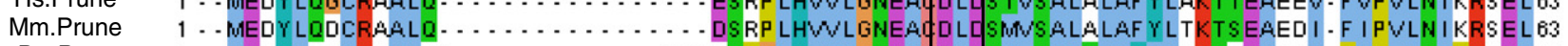

Dr. Prune $\quad 1$ - MEAYLRS CRDVLKS . . . . . . . . CSRNSP GLHWMGNEAGDMCISMVSALTFAYF LSKS LDCKRI. PVPVLNIPRAEF 67

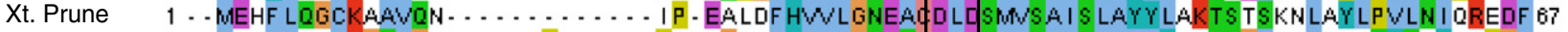

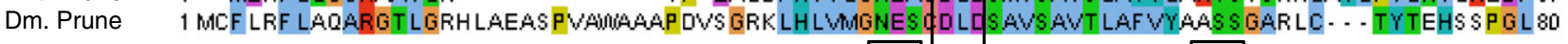

Hs.Prune 64 PLRGDIVFF LOKVHIPES ILIFRDEIDLHALYOAGQLTLI LVDHH ILSKSDTALEEAVAEVL DHF IE. . . . PKHCPPCHV140 Mm.Prune 64 P LRGDNVF LOEVK I PEPAL I FRDE I DLLALHQAGQLT L I L YDH I LPKSDAALEEAVAEVLDHE I E. . . . . OKYCPPCHV140 Dr. Prune 68 PLRSDS IF LLRESGLSODYLLFDEVDLHGLHKNKOLTLTLVDHVLPSADSELEDAWEVIDHHLLO - . . . - RPS SS - CP I 143 Xt. Prune 68 PLRTESTYF LKQNG I PEGHLIFRNE I DLQTLYESGHLVLTL LDHN VLPGDS YLEDWAEVIDHFHLE. . . . . RPAALNCKV 144

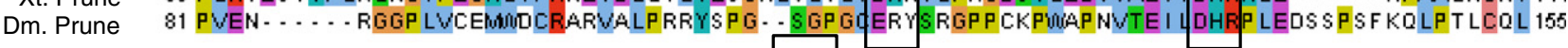

Hs.Prune 141 SVEL-VGSCAT LVTER I LQGAPEI LDRDTAAL LHGT I I LCCVNMDLKI GKATPKDSK VEKLEALFP. DLPKRNDI IDS LOKA 221 Mm.Prune 141 SVEL-VGSCAT LVTER I LQGAPET LDROTAAL LHGTI I LCCVMMDTN I GKATPKDSK VEELEALFP. DLPKRKD I HDS LOKA 221 Dr. Prune 144 TVEP - VGSCT LVTER I AOKS PAVLDOOVAOLLYGT I I LCCVNMAPEAGKVTP KDS OYAIF LEORFP. KLP PRGALP OS LONA 224 Xt. Prune 145 TSEL - VGSCT TLVAEK I I HGAPE I LDLQLAS LLRDT IVLCC I NMAPAAGKVTPKDTE WTT LESMF P - S LP P RGTVF DS LQKA 225 Dm. Prune 156 DIDASVGSCATLVADRY LAED-QPRSTSVAOLLHAT IVLCTINFAPAAKBYGPKDEAWVOKLESELNRKDAOBSS LFDELVAA 237

Hs.Prune 222 KF DVS GLTTEOMLRKDOKT I YROGVKVAISAI YMDLEAF LORSNLLADLHAF COAHS YDVLVAMT I F FNT - HNEPVROLAIFC 303 Mm.Prune 222 KF DVSGLTTEOMLRKDOKTVYROGTKVAI SAI YMDLKAF LORTDLF TDLS SF CHDHS YDALVAMT I FF NT . DNEPVROLAIF C 303 Dr. Prune 225 KF DVS G LS TEOMLLKDMKAAS GGDLR LAVSVI MMT LEDF LORS G LODDLCEF CHS HNYN LL LAMT I SF KD - SKEPF RQ LAVYS 306 Xt. Prune 220 KFDVSGLTTDOMLRKDLKLVSRD IS LAISALYMKLEDFMOKED I ESDLCSF CRRHHYNVLVAMAI IF NR. ENEPMROIAVYS 307 Dm. Prune 23e RAD I SKLTLTEVLRKDMKLLTDRQWP LAGMP I LVRDFVEKSGAEKAVREF GVESNLLVI LGMYVSPADGQVQRD LAL I S LS 320

Hs.Prune 304 PHVALOTTICEVLERSHSPPLKLTPASS - THPNLHAYL- DGNTOVSRKKLLPLLDEALSAYF DSMKIPSGQPETAD-VSREOV383 Mm.Prune 304 PHEALRMT I CGI LERSTSPP LKLTP I PS. TSPNLQAYH. QGNTQVSRKKLLPVLOEALSAYLDSAKMAS GQSEVAVGMS REOV 384

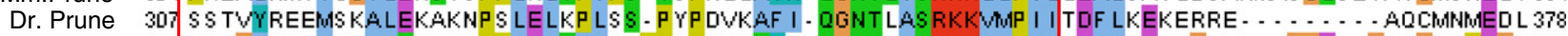
Xt. Prune 308 QKEGLRRWCKALQDATNPP LDLTAIACPPCP STTTYO- QGNTAASRKKVLP I LKDF LRERTGDDNLEGGELF GDCGEOPEGO 389

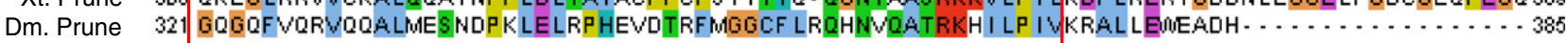

Hs.Prune 384 D. - KELDRASNS LISGLS - . - DD - EEDPP LPP TPMNS LVDECP LDOGLPKLSAEAVFEKCSOISLSOSTTASLSKK

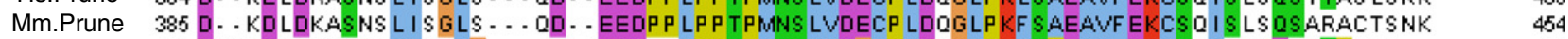
Dr. Prune 379 DLDDDSNODOSDCLEDAG. . . . . . I EDDTRVP P TPMNS LVEGCP LDNG LPK I S P EALVEKVS KMASMEDTS PEEO - . Xt. Prune 390 DGCPGEEORSKGF I GTYRTOLDDGLEDERSFP TPMNS LVEGCP LDRGLPKLTAEAI LERF SHITAIDSESOSGGEK

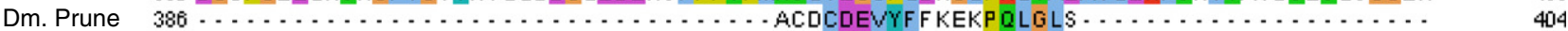

\section{B}

NM23-H1

NM23-M1

NM23-X

NM23-X2

1 - MANCERTF I AI KP DGVQRGLVGE I I KRF EOKGFRLVGLKFMOASEDLLKEHYDLKDRPF FAGLVKYMHS GPWAMMUEG LNW84 1 - WANS ERTF IAI KP DGVORG LVGEI I KRF EOKGF RLVGLKF LOASEDLLKEHYTDLKDRPF F TG LVKYMHS GPWAMWUEG LNW84 1 MAANKERTF I A I KP DGVORG LMGD I I KRF EOKGF RLVAMKF LOAS QDLLROHY I DLKDRP F YP GLVEYMNS GPVLAMMMEG LNW85 1 MAANKERTF I A I KP DGVQRG LMGD I I KRF EOKGF RLVAMKF LOAS QDLLRQHY I DLKDRPF YP GLVEYMNS GPVLAMWUEG LNW85

NM23-H1 85 KTGRMMLGETNPADS KP GT I RGDF C I OVGRN I I HGS DSVESAEKE I GLDUF HPEELVDYTS CAOMUII YE.

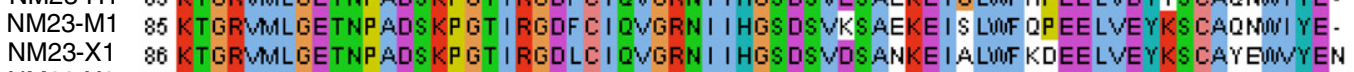

NM23-X2 86 KTGRMMLGETNPADS KP GT I RGDLCI QVGRNI I HGSDSVDSANKE I ALLOFF KDEELVEYKS CAYEMNYEN

C

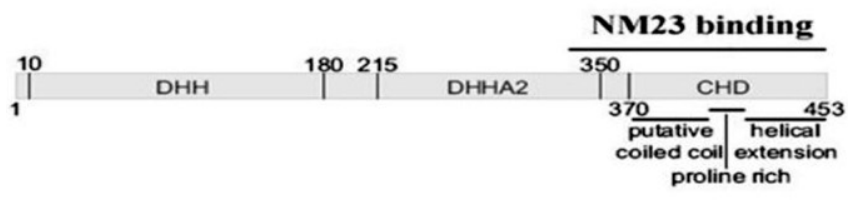

D

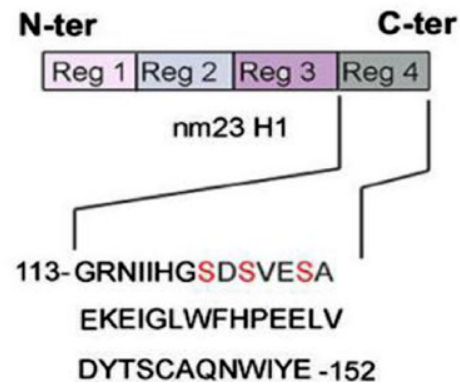

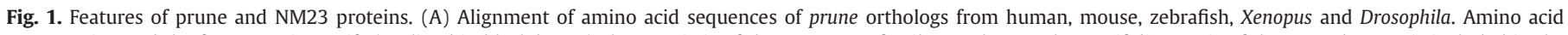

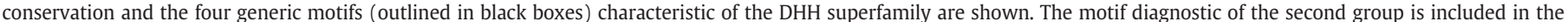

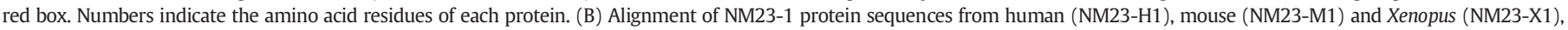
and NM23-2 from Xenopus (NM23-X2). (C) Schematic representation of prune and (D) NM23 protein structures highlighting conserved motifs and the respective interacting domains.

important for retinal function and maturation are expressed in the central retina (Ohnuma et al., 2002a; Perron et al., 1998). Based on this, our expression analysis suggests that X-prune has important roles in both cell fate determination and function of differentiated retinal cells.

Next, we examined protein expression by whole mount immunostaining and compared it with mRNA distribution. We have shown that the h-prune polyclonal antibody A59 raised against a peptide corresponding to its DHR motif (Fig. 4A) and NM23-H1 antibody (K73) (Supplemental Fig. 4B) are able to detect proteins of the same size in protein extracts from Xenopus laevis (Garzia et al., 2008). Additional analyses to address specificity of the antibodies used in these studies are presented on Supplemental Figs. 4A-B and Figs. 5A-C. As expected, the Supplemental Fig. 4A shows a main prune cross reaction within $60 \mathrm{kDa}$ molecular weight of additional immunoreactions observed at lower molecular weight (in the most bottom part of the panel). This is because there are occurring prune proteolytic protein fragmentations. Furthermore, Supplemental Figs. 5A-C show that overexpressed X-prune protein is clearly detected by the A59 h-prune antibody in Xenopus retina. 

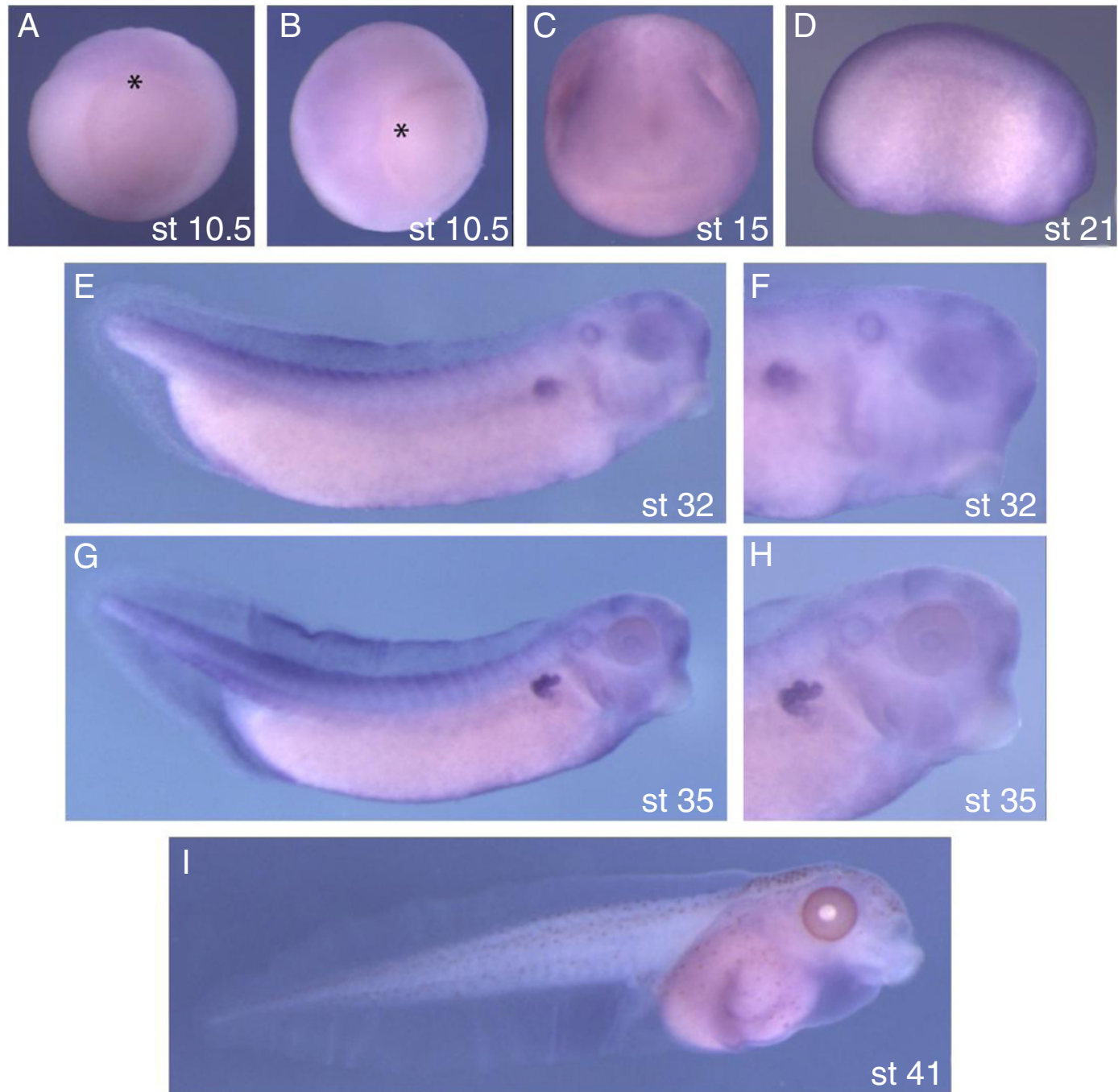

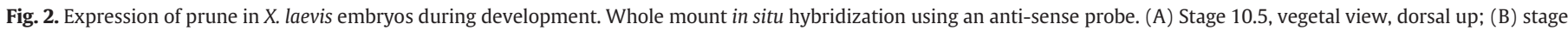

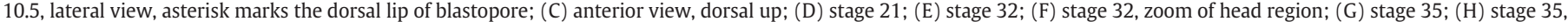
zoom of the head; (I) stage 41 tadpole. All views of (D-I) are lateral, anterior to the right.

Whole mount embryos at stages 24,32 and 45 incubated with anti-prune polyclonal antibody showed high level of fluorescence in the developing eye, otic vesicles, branchial arches and somites (Fig. 4B, top panel). Comparison of this staining, stage by stage, with the whole mount in situ hybridization (Fig. 4B, middle panel) indicates that mRNA and X-prune protein have very similar localization during embryogenesis. We also stained embryos with NM23-H1 antibody, which cross-reacts with Xenopus NM23-X1 (Fig. 4B, bottom panel). The fluorescent staining of NM23 antibody is very similar to the prune staining during embryogenesis, suggesting that NM23-X1 protein co-localizes with X-prune.

To determine the expression pattern of X-prune and NM23 proteins more precisely during eye formation, we performed an immunofluorescence analysis on retinal sections of Xenopus embryos. We observed an X-prune and NM23-X1 overlapping expression in the presumptive retinal pigment epithelium (RPE), neural retina, and optic stalk of stage 24 optic vesicles (Fig. $5 \mathrm{~A}$ ). By stage 24 , the optic vesicle has evaginated from the neural tube and makes contact with the overlying epidermis. The undifferentiated cells of the optic stalk (OS), presumptive RPE, and neural retina (NR) express both genes (Fig. 5A, first column). At stage 32, the transverse sections show that the X-prune expression is spread throughout the proliferating retina, with highest levels in the developing outer portion, in ventral region and lens and weaker expression in the presumptive RGC layer adjacent to the lens (Fig. 5B). At this stage, some retinal cell fates such as retinal ganglion cells and amacrine cells have been determined while a number of cells are still being generated in the central retina. The expression in these differentiating neuron layers is confirmed by the immunostaining with tubulin, a specific marker for neurons beginning to differentiate (Zuber et al., 1999) (Fig. 5B). Retinal lamination was clearly present by larval stage 41 . The cell bodies in the ONL, INL, and GCL were clearly outlined by immunoreactivities for both X-prune and NM23, with the ONL as well as the IPL and GCL displaying more intense levels of immunoreactivities (Fig. 5C). Radially oriented cells with morphologies reminiscent of the Müller glial cells, evidenced by anti-tubulin immunostaining (Fig. 5C), were also found positive for both proteins (Fig. 5C). To confirm the expression in GCL we also performed an immunostaining with anti-islet-1, a specific marker of retinal ganglion cells. During retinal development, $\mathrm{X}$-prune staining is largely consistent with those obtained by NM23$\mathrm{H} 1$ antibody staining, suggesting that X-prune may functionally interact with Nm23-X1 during maturation and maintenance of central retinal neurons and glial cells. Interestingly, at stage $41, \mathrm{X}$-prune staining at the peripheral CMZ is weaker than at the central differentiated retina. This contrasts with staining obtained by in situ hybridization (Fig. 3), suggesting that X-prune protein in early differentiating 

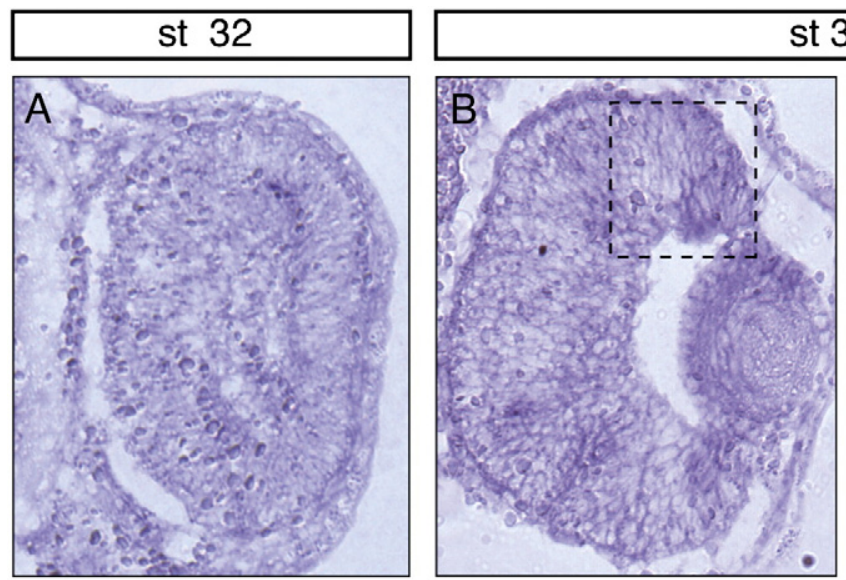

\section{st 36}
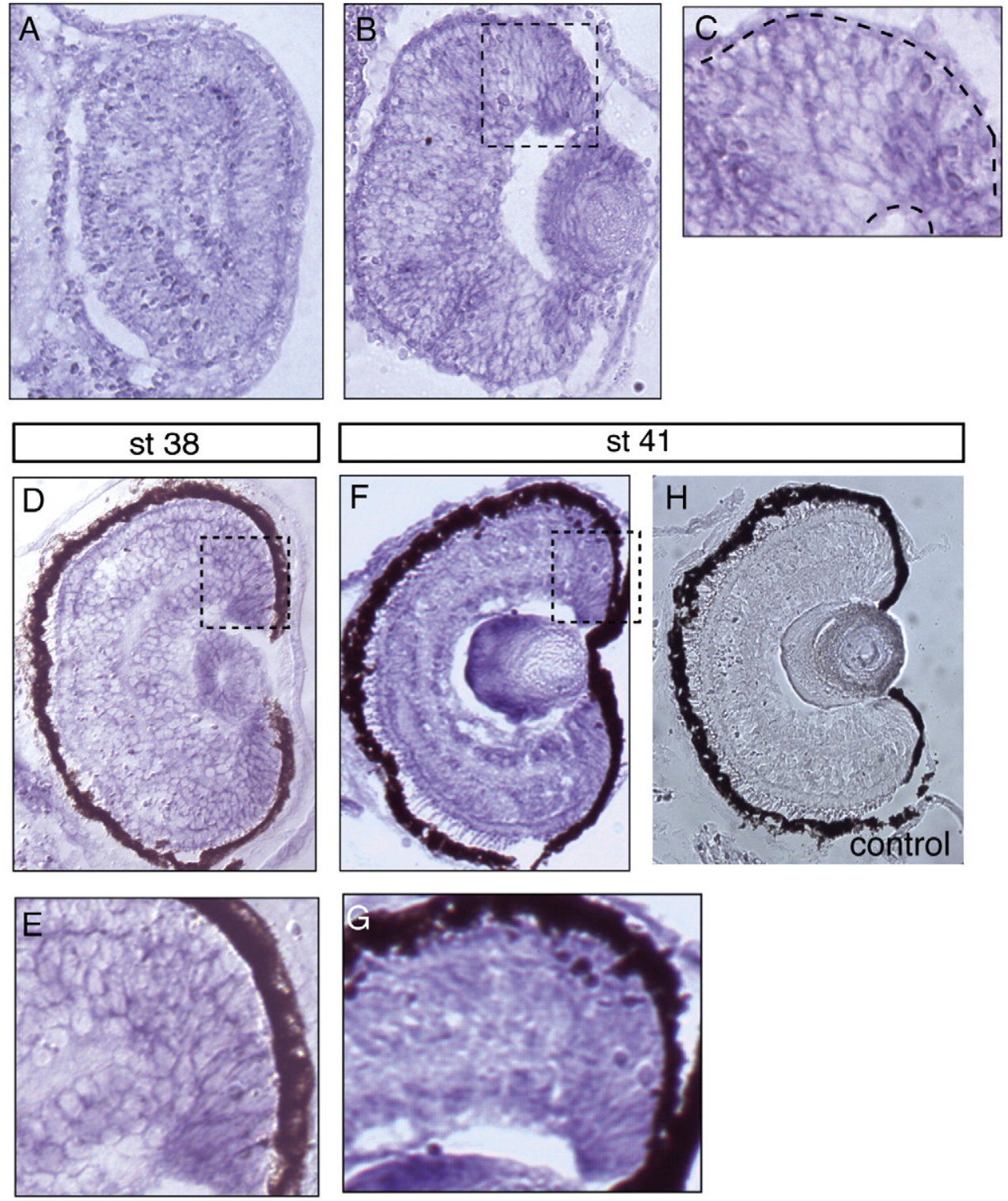

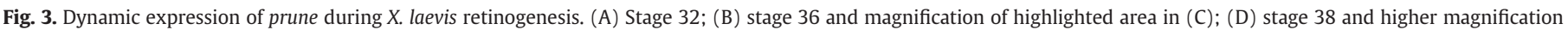

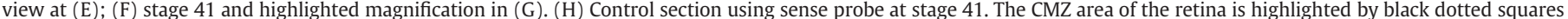
in (B), (D) and (F) and shown in magnified views in (C), (E) and (G) respectively.

retinal precursor cells might be unstable. This may fit with our observation of X-prune gliogenic activity (see next section). Also, it is important to mention that NM23-H1 antibody is unlikely to react with NM23-X3 and X4, which are highly expressed in the CMZ, because of their significant sequence differences (Bilitou et al., 2009).

\subsection{Prune overexpression increases the ratio of Müller glial cells}

Our expression analysis indicates that X-prune is expressed in undifferentiated precursor retinal cells and differentiated neurons and glial cells. NM23-X4 and X3 are expressed in undifferentiated cells in the CMZ and NM23-X1 is expressed in embryonic retinal precursor cells (Mochizuki et al., 2009). Our previous studies have shown that all NM23 family members in Xenopus have the ability to modulate retinal cell fate determination (Mochizuki et al., 2009), suggesting that prune may have an ability to modulate cell fate determination through its interaction with NM23 proteins. Therefore, we have investigated prune's ability to modulate retinal cell fate determination.

The expression construct of h-prune was co-lipofected with GFP expressing plasmid to the eye primordia of stage 15 Xenopus embryos. This technique enables to co-express prune and GFP in a small percentage of retinal precursor cells in vivo (Holt et al., 1990; Ohnuma et al., 2002b). Since co-lipofection efficiency is very high (more than 95\%), we can identify prune overexpressing cells based on GFP fluorescence. After development of the lipofected embryos until stage 41, when retinal differentiation of central retina is completed, the embryos were fixed and sectioned. Then, differentiated cell types of GFP/prunepositive cells at the central retina were identified based on the morphology and nuclear position of the cells.

We have found a high proportion of retinal cells that have cell bodies in the inner nuclear layer and complex processes spreading from the retinal ganglion layer to outer nuclear layer (Figs. 6A-B). This cell morphology, characteristic of Müller glial cells, was confirmed 

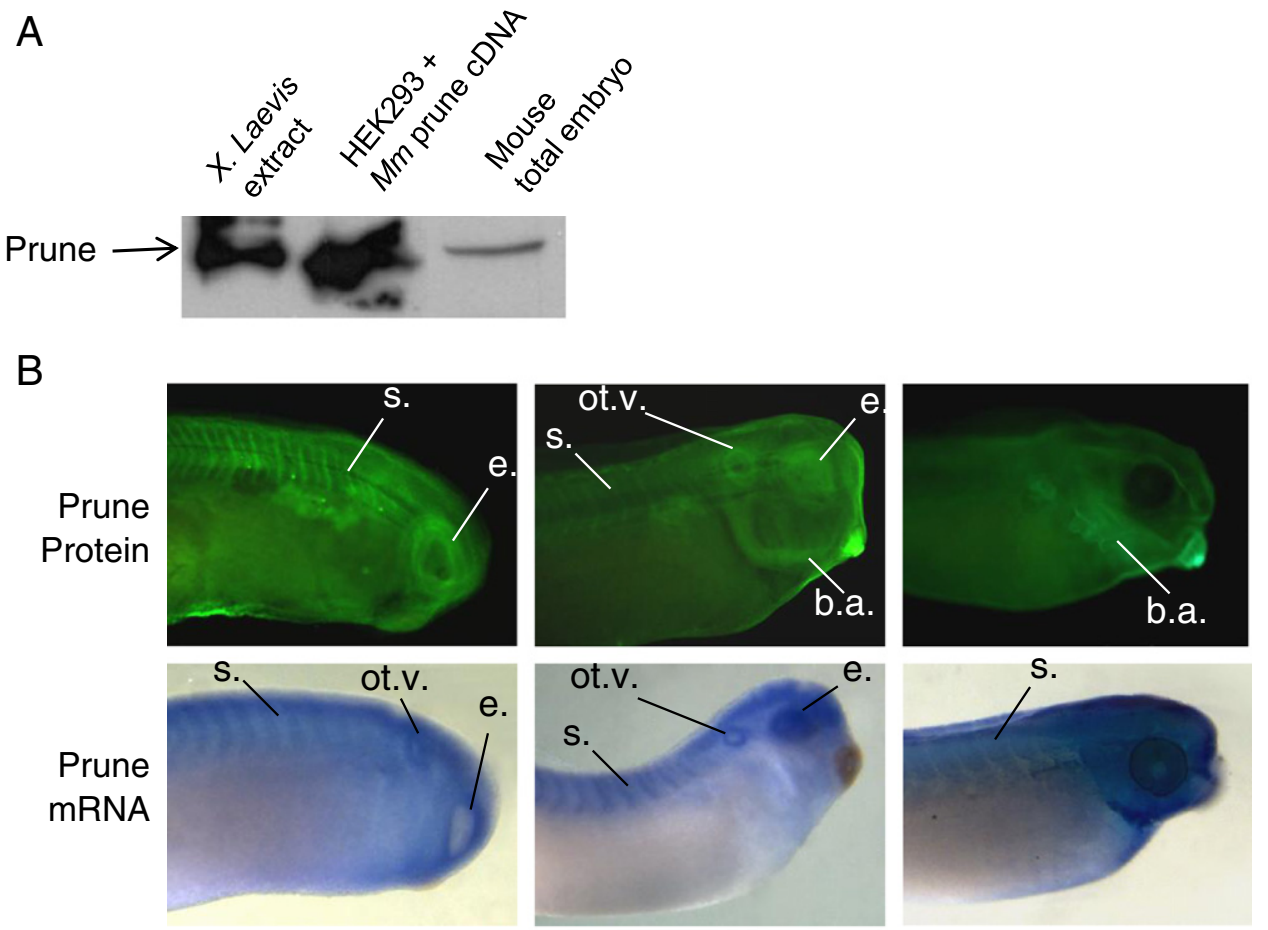

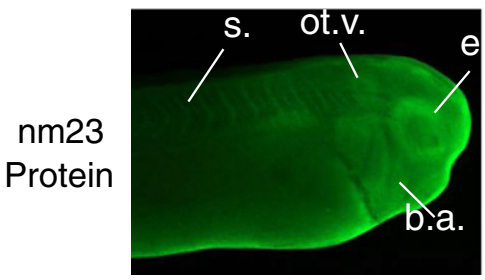

Stage 24

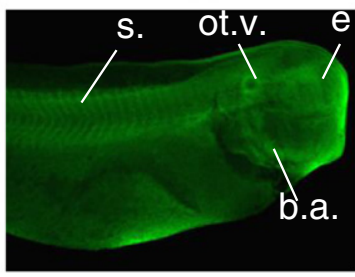

Stage 32

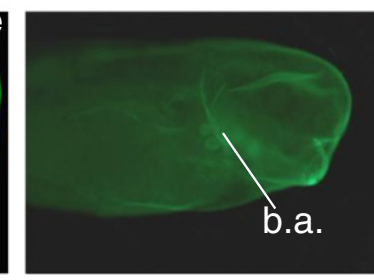

Stage 45

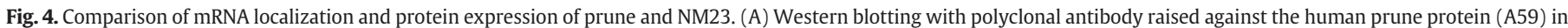

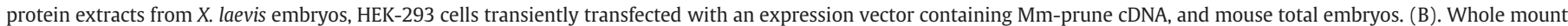

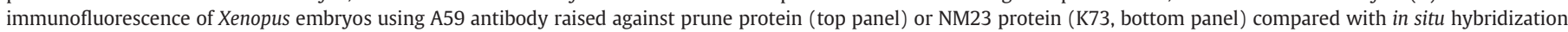

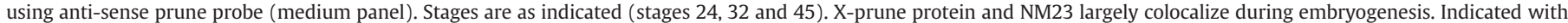
white lines are the eye (e), the otic vesicle (otv), the branchial arches (ba) and the somites (s).

by immunostaining using the R5 antibody (Figs. 6F-H) and the antiglutamine synthetase antibody (Figs. 6I-K), specific Müller glial cell marker (Jablonski and Iannaccone, 2000; Ohnuma et al., 1999). Also, we confirmed that h-prune is indeed overexpressed in the GFP positive lipofected cells by the A59 antibody. Figs. 6C-E show that the GFP positive cells are also A59 positive.

Finally, to confirm the increase of Müller glial cells, the ratios of all retinal cell types were determined (Fig. 6L). From the graph it is evident that prune overexpression causes a two-fold increase in Müller glial cells $(12.56 \% \pm 0.12)$ compared to GFP control $(5.78 \% \pm 0.6$, $\left.\mathrm{p}<0.01,{ }^{* *}\right)$ at the expense of bipolar cells $(29.29 \% \pm 3$ compared to $36.5 \% \pm 2.6$ of GFP only). These results indicate that prune has the ability to modulate retinal cell fate determination. The same results were obtained when the Xenopus expression construct, tagged or untagged, was lipofected (data not shown).
2.4. Phosphodiesterase activity of prune may be required for the prune mediated regulation of gliogenesis

Next, we wanted to analyze the molecular basis of prune gliogenic activity. It is known that prune protein has four conserved aspartate residues in the $\mathrm{N}$-terminal side (Figs. $1 \mathrm{~A}$ and $7 \mathrm{~A}$ ), which are essential for phosphodiesterase activity of cAMP (D'Angelo et al., 2004). As shown in Fig. 7A, the mutant 4D Delta $(4 \mathrm{D} \Delta \mathrm{m})$ that bears substitution of all 4 aspartate residues with alanine could not increase the ratio of Müller glial cells. Previous work showed that prune protein interacts with the proteins NM23-H1 and glycogen synthase kinase-3 beta (GSK-3 3 through its C-terminal side) (Fig. 7A). Thus, we examined the effect of the $\mathrm{N}$-terminal and $\mathrm{C}$-terminal mutants in cell fate determination. As shown in Fig. 7B, the N-terminal mutant does increase Müller glial cells although the activity is slightly weaker than that of 
A

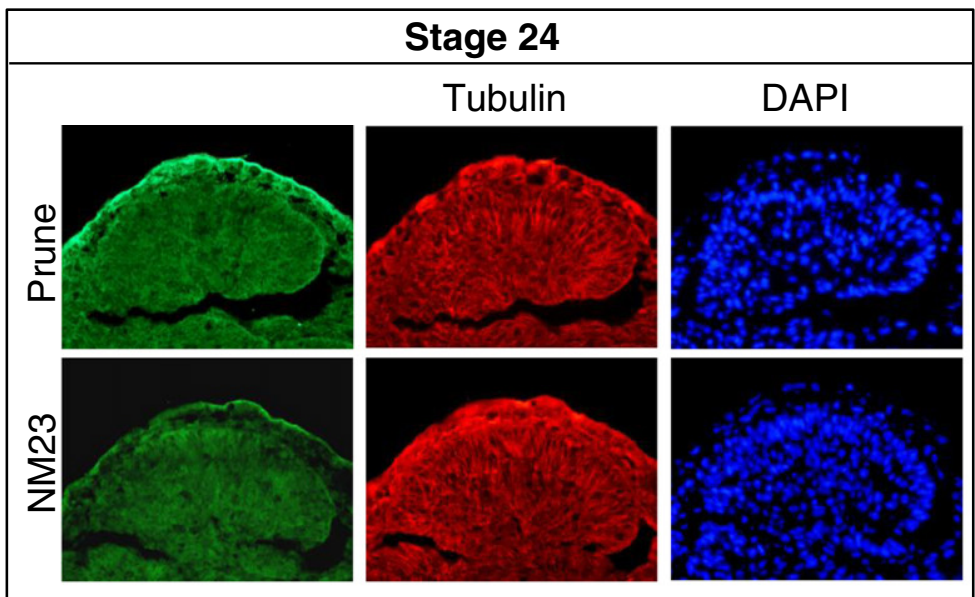

B

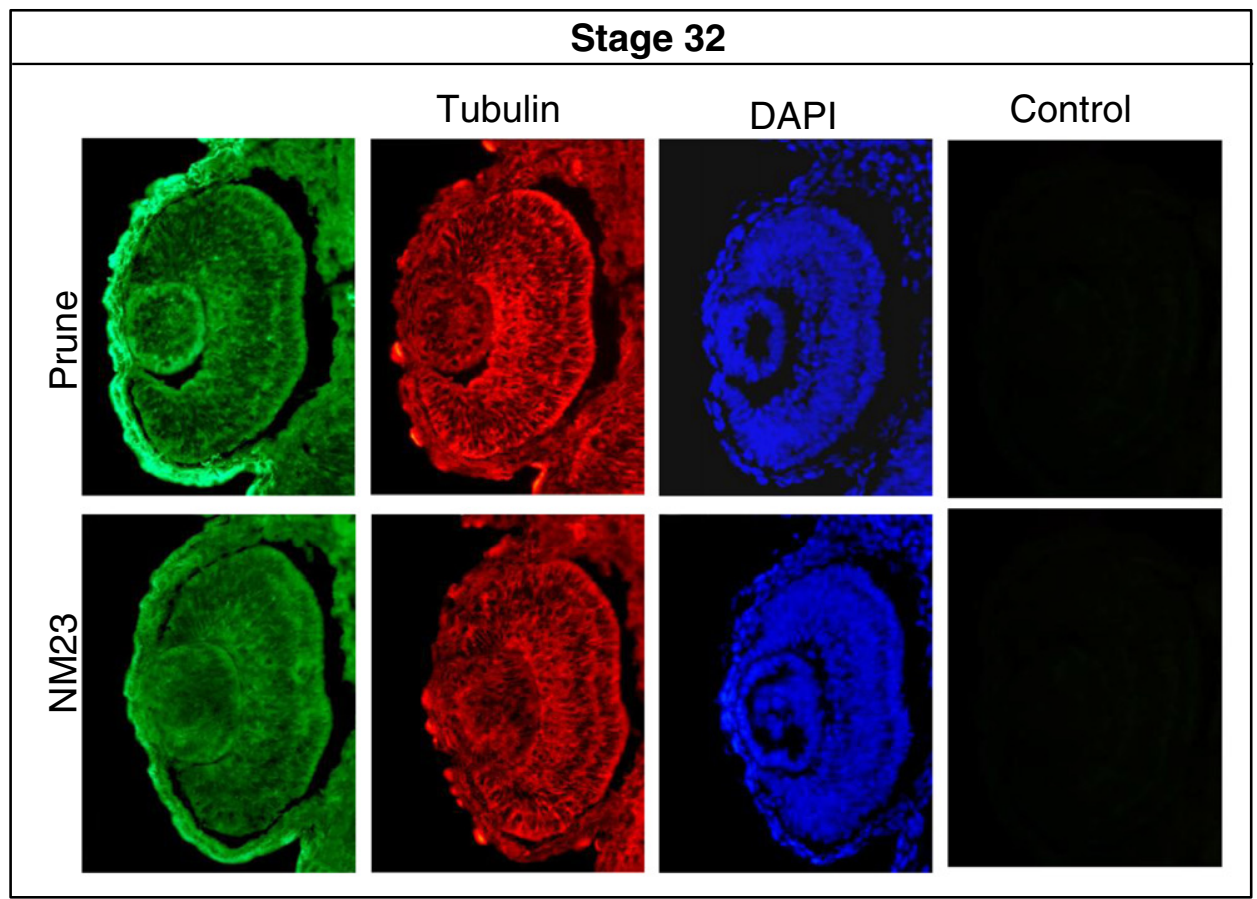

C

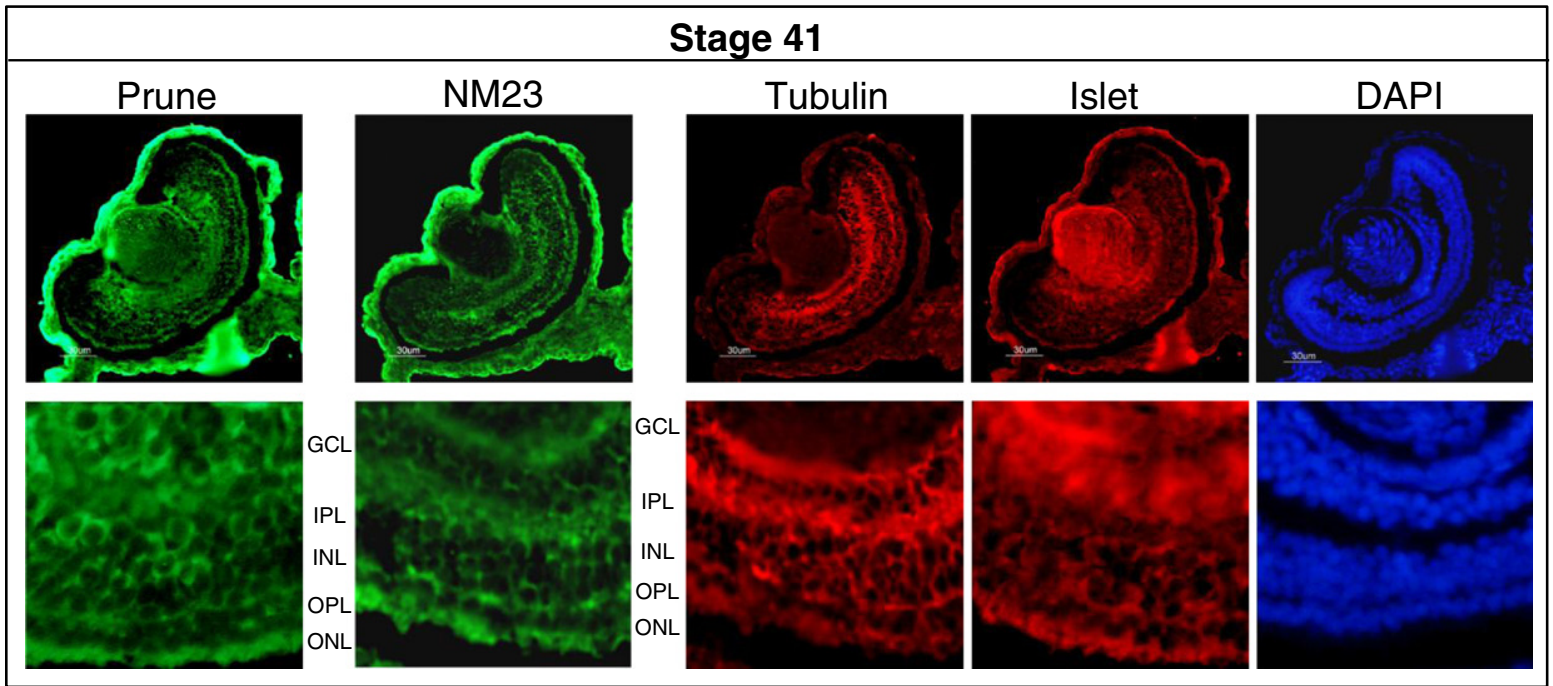



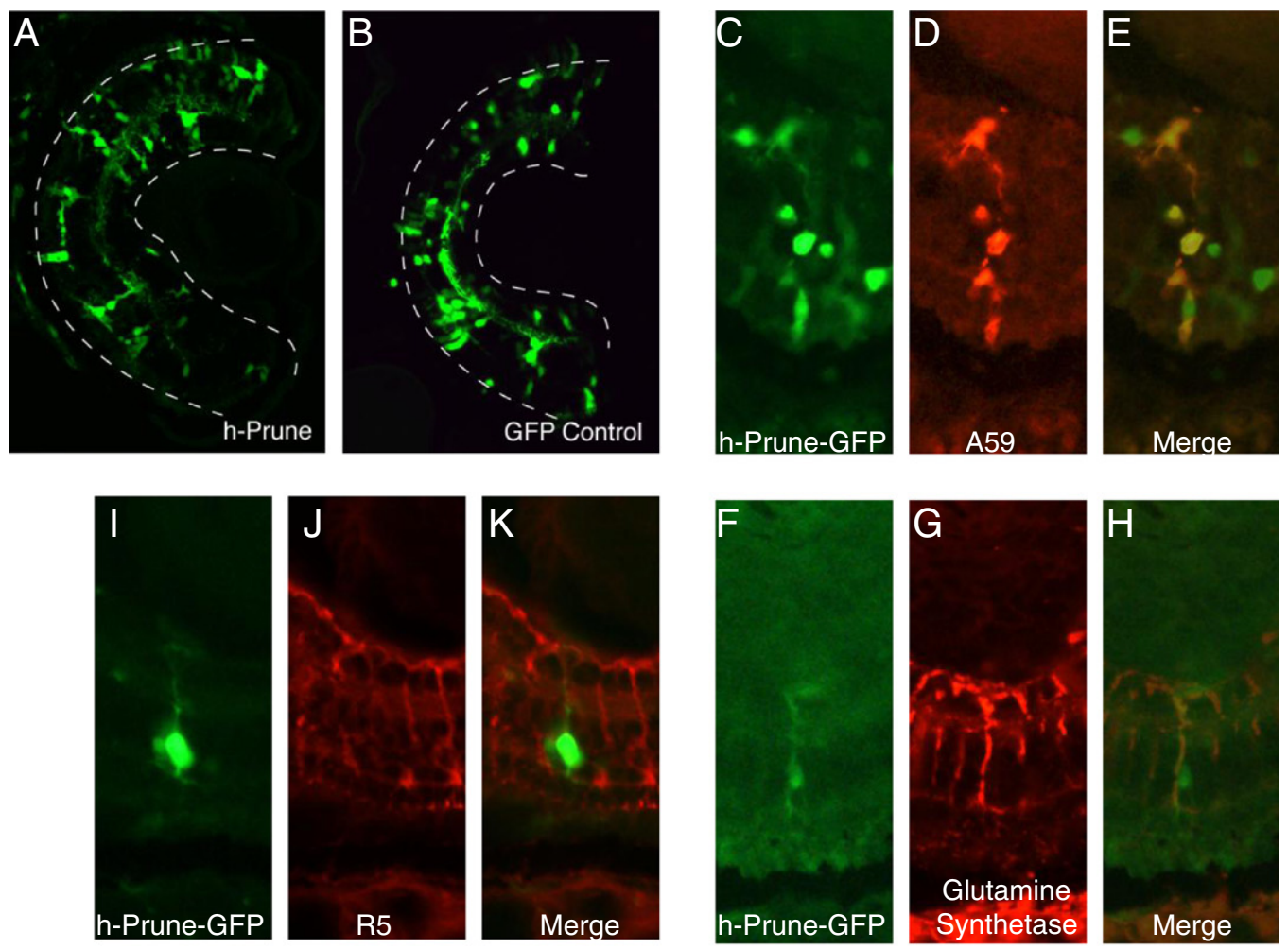

L

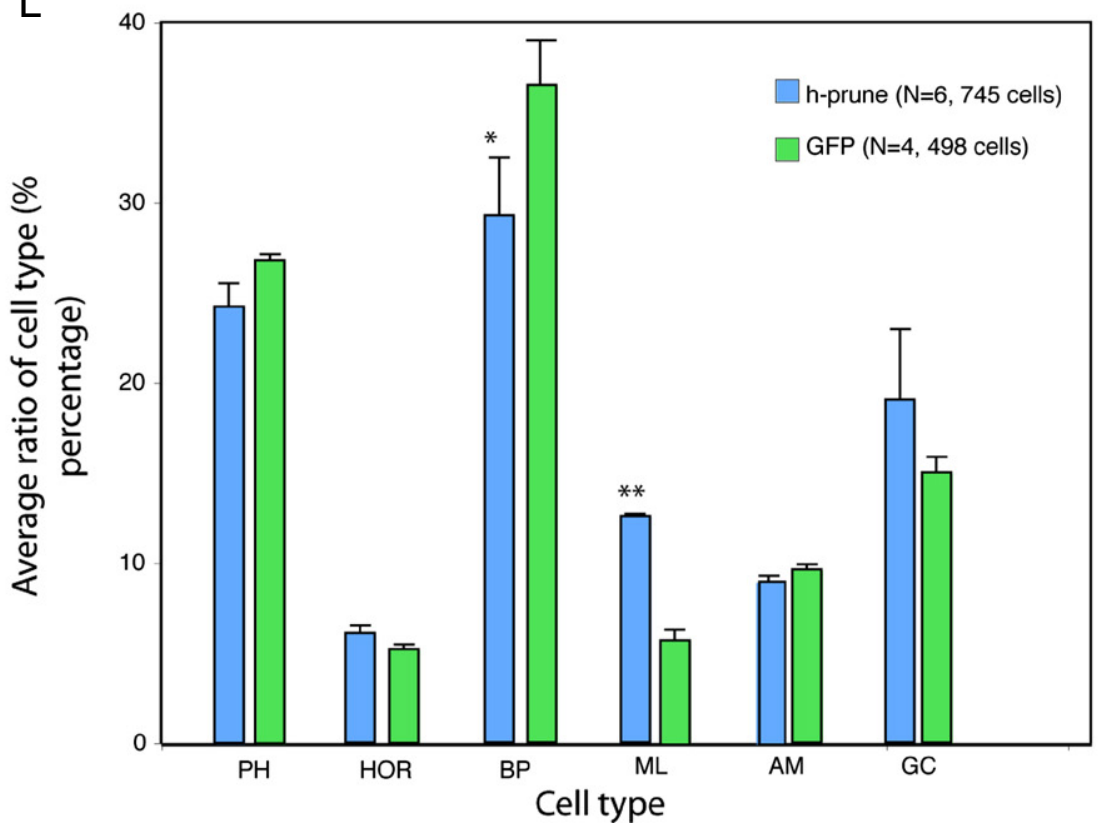

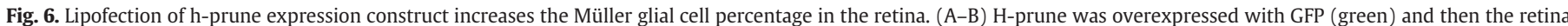

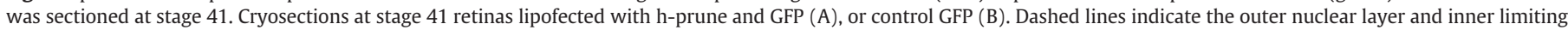

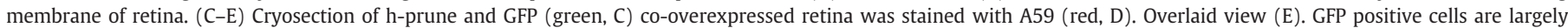

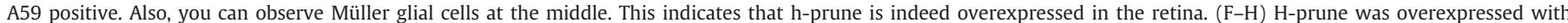

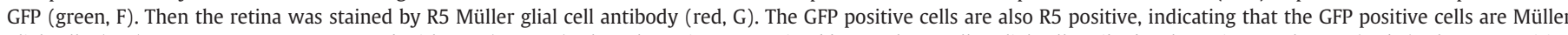

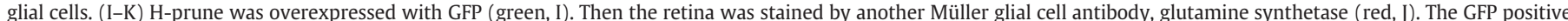

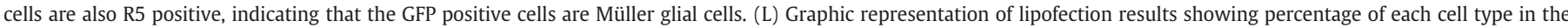

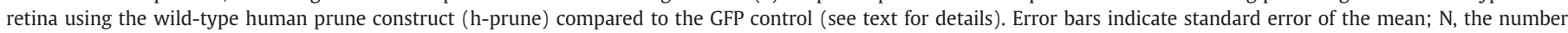

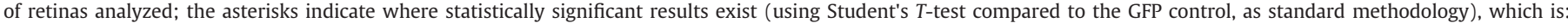
${ }^{*}$ for $\mathrm{p}<0.05,{ }^{* *}$ and for $\mathrm{p}<0.01$. PH, photoreceptor cells; HOR, horizontal cells; BP, bipolar cells; ML, Müller glia cells; AM, amacrine cells; GC, ganglion cells.

wild type, while the C-terminal mutant cannot change the ratio of Müller glial cells. These mutational analyses suggest that the $\mathrm{N}$-terminal side of prune and possibly its phosphodiesterase and exopolyphosphatase activities located there, are important for the regulation of retinal cell fate. Fig. 7 demonstrates that the 4DD-mutant does not increase the Müller glial percentage $(2.96 \% \pm 1.04, \mathrm{p}=0.28)$ compared to the GFP 

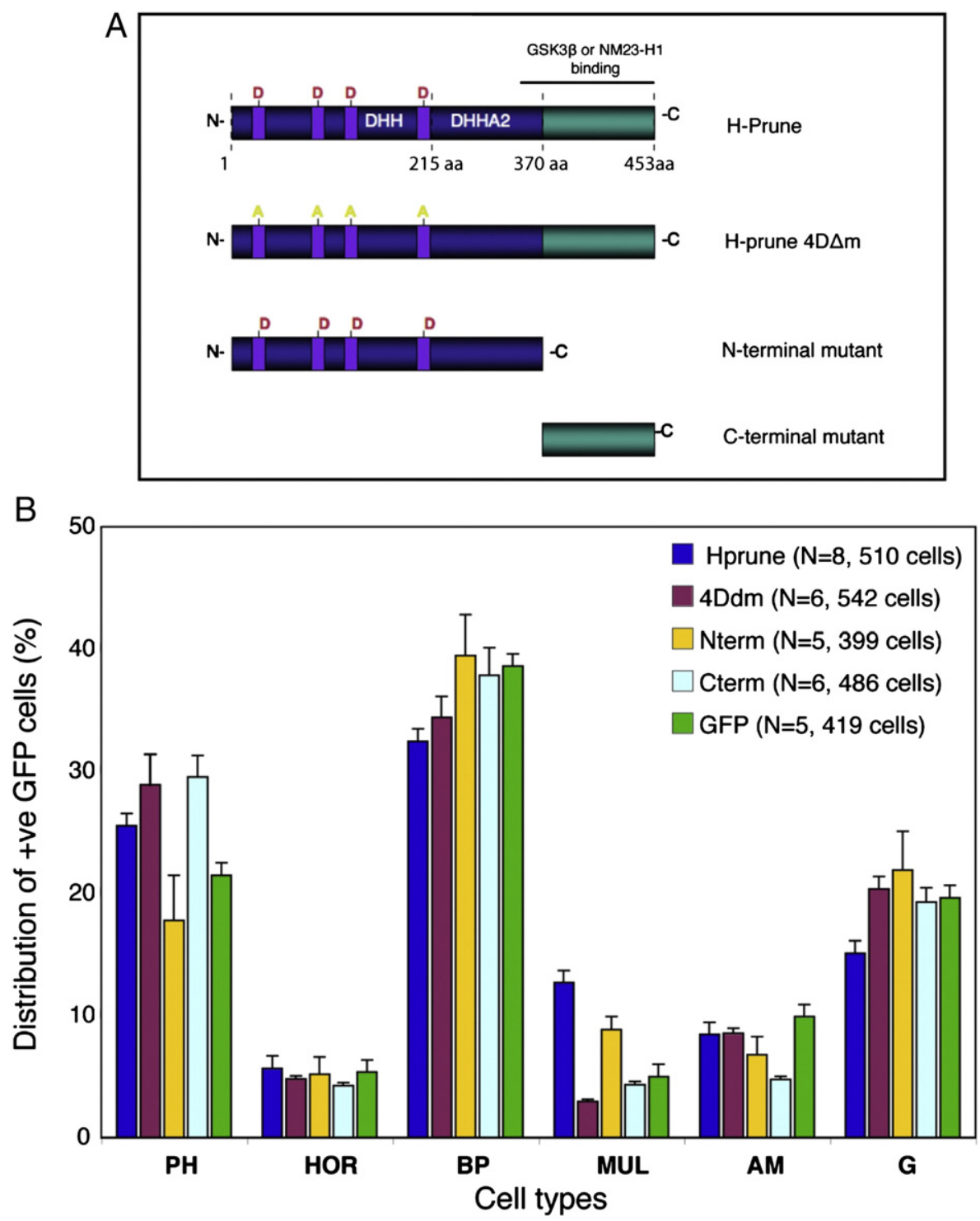

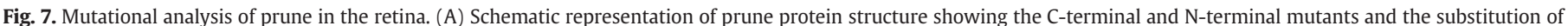

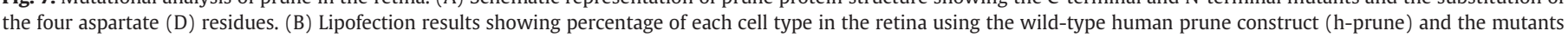

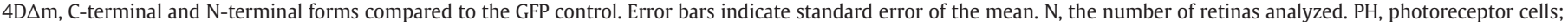
HOR, horizontal cells; BP, bipolar cells; ML, Müller glial cells; AM, amacrine cells; G, retinal Ganglion cells.

control $(4.98 \% \pm 1.1)$. The mutant causes a slight increase of photoreceptors $(28.88 \% \pm 4$, compared to $21.5 \% \pm 2.88$ of GFP), which is not significant $(p=0.31)$ and does not affect percentages of the other cell types. For comparison, the wild-type h-prune was lipofected and, as previously shown, it does increase the Müller glial cell $\left(12.69 \pm 1.47, \mathrm{p}=0.02,{ }^{*}\right)$ and the decrease of bipolar cells $(32.48 \% \pm 2.4$, compared to $38.62 \% \pm$ $2.2, \mathrm{p}=0.1$ ) was also observed. Therefore, this data suggest that the existence of the four aspartic acid residues that comprise the catalytic motif of PDE is required for h-prune to exert its gliogenic effect in the retina, although the data is not yet reaching statistical significance. Lipofection of the N-terminal mutant increased the Müller glial cell percentage but not significantly $(8.83 \% \pm 2.1, \mathrm{p}=0.19)$. This result suggests that an intact PDE domain contributes but is not sufficient to exert the gliogenic phenotype of prune, implying that the C-terminal part of the protein is also required for this effect. Consequently, the C-terminal mutant was lipofected to examine the effect in cell type distribution. As it is shown in Fig. 7, overexpression of the C-terminal prune alone does not affect the Müller glial cell percentage or any other cell types significantly. This result suggests that the dimerization domain alone or the knowledge of GSK3 negative functional regulation is not sufficient to affect cell fate determination in the retina.

\section{Discussion}

Our study shows that prune is expressed in both undifferentiated precursor cells and differentiated cells during Xenopus retinal development. We also show that prune protein has an ability to increase Müller glial cells, suggesting that it may have a role in retinal cell fate determination. Moreover, the phosphodiesterase and exopolyphosphatase activities located at the N-terminal side are important for increase of Müller glial cells.

Prune participates in the complex network of interactions with proteins involved in multiple developmental processes. We might assume that prune-mediated potentiation of Müller gliogenesis through its physical interaction with NM23 family members. We previously showed that NM23 family members have the ability to modulate Müller gliogenesis in both cyclin dependent kinase inhibitor-dependent and independent manners (Mochizuki et al., 2009). In the case of the dependent 
manner, NM23 functions as an inhibitor of gliogenesis, while, in the independent manner, NM23 functions an activator of gliogenesis. In this NM23 context, we might assume that prune might control positively this pro-gliogenesis function as already postulated to be controlling the anti-motility action of NM23-H1 in cancer (D'Angelo et al., 2004).

H-prune interacts with GSK-3 $\beta$ (Garzia et al., 2006; Kobayashi et al., 2006), a protein kinase with a peculiar function in the inhibition of the canonical Wnt pathway with roles in cell specification in a variety of tissues (Ciani and Salinas, 2005) (Boyle et al., 1991) including retina. This may propose that prune regulates gliogenesis through interaction with the canonical Wnt pathway. However, Fig. 7 shows that the h-prune C-term mutant construct, which binds both GSK$3 \beta$ and NM23-H1, does not affect the enhancement of the Müller gliogenesis, while the construct of the h-prune N-term mutant has the gliogenic activity similar to that of the full-length h-prune construct. This may suggest that GSK-3 $\beta$ may not be involved in the gliogenic activity. Furthermore, we don't know how the phosphodiesterase activity of prune influences gliogenesis. Although our study clearly indicates the potential of prune in retinal cell fate determination, we have opened the path for further studies required to elucidate the clear molecular mechanism.

\section{Materials and methods}

\subsection{Materials}

Prune antibody, A-59, was originally raised against human prune protein (D'Angelo et al., 2004). NM23 antibody, K73, was originally raised against mouse NM23-M1 (D'Angelo et al., 2004). These antibodies were preabsorbed with $X$. laevis embryonic extract at 1:1 ratio. The absorbed antibodies of A59 and K73 were used for this study showing specificity R5 antibody (Ohnuma et al., 1999) and glutamine synthetase (MAB302, Millipore) (Jablonski and lannaccone, 2000).

\subsection{Xenopus}

Animals were utilized according to the guidelines and policies dictated by the University Animal Welfare Office and in agreement with international regulations. Xenopus embryos were obtained by in vitro fertilization as described (De Marco et al., 2011) dejellied with $2 \%$ cysteine, maintained in $0.1 \times$ MBS and staged according to Nieuwkoop and Faber (1967).

\subsection{Lipofection}

Lipofection into eye primordia was performed as described (Ohnuma et al., 2002b). For tracing the cells, pGFP plasmid was co-transfected with other plasmids since co-lipofection efficiency is more than $95 \%$. In some cases, co-lipofection was confirmed by immunohistochemistry using myc-tagged constructs. We performed each experiment at least three times.

\subsection{Preparation of cryosections from embryos}

Staged embryos were fixed in $4 \%$ paraformaldehyde in $1 \times$ PBS for $1 \mathrm{~h}$ at room temperature (RT), washed briefly in $1 \times$ PBS and cryoprotected in $30 \%$ sucrose/PBS for $1 \mathrm{~h}$. All traces of the solution were aspirated and the embryos were oriented and embedded in Tissue-Tek O.C.T. compound (Ted Pella Inc., Redding, CA, USA) to make compact blocks. The blocks were then cut at $10 \mu \mathrm{m}$ transverse sections with anterior to posterior direction on a cryostat (Leica CM1900). Cryosections were either counterstained with Hoechst 33342 vital nuclear stain and mounted with coverslips, or stored intact at $-20{ }^{\circ} \mathrm{C}$ until use in immunostainings or in situ hybridization assay.

\subsection{Western blots}

$X$. laevis embryos were homogenized in a HEPES buffer $\mathrm{pH} 7.5$ containing $900 \mathrm{mM}$ glycerol, $0.02 \mathrm{mM} \mathrm{NaN}_{3}, 1 \mathrm{mM}$ ATP, $1 \mathrm{mM}$ DTT, $5 \mathrm{mM}$ EGTA and the following protease inhibitors (Sigma): $2 \mathrm{mM}$ TAME, $5 \mathrm{mg} / \mathrm{ml} \mathrm{SBTI,} 5 \mu \mathrm{g} / \mathrm{ml}$ aprotinin and $10 \mu \mathrm{M}$ E64. After centrifugation at $13,000 \mathrm{rpm}$ for $40 \mathrm{~min}$ at $4{ }^{\circ} \mathrm{C}$, proteins were boiled for 5 min in reducing sample buffer, separated in 8\% SDS-PAGE, and electroblotted on nitrocellulose membranes (Schleicher \& Schuell). The membrane was blocked in 3\% bovine serum albumin overnight $(\mathrm{o} / \mathrm{n})$ at $4{ }^{\circ} \mathrm{C}$. Incubation with specific antibody was performed using polyclonal A59 and K73 antibodies. Antibody binding was detected with a secondary anti-rabbit IgG coupled with alkaline phosphatase (Sigma) followed by visualization with NBT/BCIP (Pierce).

\subsection{Cell culture, transfection and immunoprecipitation}

HEK-293 were cultured in Dulbecco's Modified Eagle's Medium (Gibco) supplemented with $10 \%$ fetal bovine serum (FBS), $100 \mathrm{U} / \mathrm{ml}$ penicillin, and $100 \mu \mathrm{g} / \mathrm{ml}$ streptomycin (Gibco), at $37{ }^{\circ} \mathrm{C}$ with $5 \% \mathrm{CO}_{2}$. X-prune cloned in pcS4-3XFLAG and NM23-X2 cloned in Ha-pcDNA were transfected in HEK293 cells with $\mathrm{CaCl}_{2}$. The cells were harvested $48 \mathrm{~h}$ after transfection and the total cell lysates were obtained with the standard protocol of lysing the cells in $20 \mathrm{mM}$ Tris- $\mathrm{HCl}, 2 \mathrm{mM}$ $\mathrm{MgAc}, 0.3 \mathrm{mM} \mathrm{CaCl}, 1 \mathrm{mM}$ DTT, $2 \mu \mathrm{g} / \mathrm{ml}$ pepstatin, $2 \mu \mathrm{g} / \mathrm{ml}$ aprotinin, $2 \mu \mathrm{g} / \mathrm{ml}$ leupeptin, $1 \mathrm{mM} \mathrm{NaF}$, and $1 \mathrm{mM} \mathrm{NaVO}_{3}$. The immunoprecipitation was performed with anti-HA monoclonal antibody (Sigma), in quantities of $1 \mathrm{mg}$ of total cell extract.

\subsection{Immunohistochemistry}

$X$. laevis embryos were fixed in $4 \%$ formaldehyde at $4{ }^{\circ} \mathrm{C}$. For whole mount immunofluorescence, after bleaching in $\mathrm{H}_{2} \mathrm{O}_{2} / \mathrm{MeOH}(1: 2)$, the embryos were incubated for $24 \mathrm{~h}$ at $4{ }^{\circ} \mathrm{C}$, with $\mathrm{A} 59$ (1:100) or K73 (1:50). The samples were washed in PBS and incubated with BODIPY FL-conjugated anti-rabbit goat IgG (Molecular Probe) for $24 \mathrm{~h}$ at $4{ }^{\circ} \mathrm{C}$. Embryos were washed in PBS, dehydrated in graded $\mathrm{MeOH}$ and cleared in benzyl alcohol:benzylbenzoate (1:2). For immunofluorescence on sections, $10 \mu \mathrm{m}$ thick sections were obtained. Unspecific background was blocked by incubating the sections for 30 min in 3\% normal goat serum in PBS, 0.5\% BSA, 0.1\% Tween-80, prior exposure to A59 or K73, monoclonal anti- $\beta$-tubulin III (Tuj 1, Sigma) (1:500), mouse anti-islet (1:100), R5 antibody (1:1), antiglutamine synthetase (1:500) diluted in PBS containing 0.5\% BSA, and $0.1 \%$ Tween- $80 \mathrm{o} / \mathrm{n}$ at $4{ }^{\circ} \mathrm{C}$. Staining was completed by incubation with anti-rabbit goat IgG BODIPY FL-conjugated or Texas Redconjugated anti-mouse goat antibodies (Molecular Probe) for $1 \mathrm{~h}$ at RT. Nuclei were counterstained with DAPI (1:1000) for $10 \mathrm{~min}$ at RT. Sections were mounted in PBS-glycerol.

\subsection{In situ hybridization}

$X$. laevis total RNA was extracted from several embryonic stages with TRI Reagent (Sigma). RT-PCR was performed with Superscript First Strand RT-PCR (Invitrogen). A 185 bp fragment of X-prune was amplified from cDNAs (using the primers $5^{\prime}$-AAAAAGGTTGGAGGAC CATT-3' and 5'-CCTGAAAACCATGAGGACTTG-3'), cloned into pDRIVE vector (Qiagen) and sequenced by PRIMM (Naples, Italy). X-prune fragment was cut with Sall or BamHI and used as template to synthesize digoxigenin-labeled RNA antisense and sense probes, with digoxigenin-labeled UTP and T7 or Sp6 polymerase, according to the manufacturer's recommendations (Roche).

Whole mount was carried out as described by Harland (1991). A $X$. laevis EST clone was obtained as IMAGE clone and was used to prepare probes for in situ hybridization (EST AGENCOURT_13842565, IMAGE: 6932471). Briefly a $1.7 \mathrm{~kb}$ cDNA fragment in pDNR-LIB vector 
was recloned in pBluescript II KS. The plasmid was then linearized with Kpn I or Not I and used to prepare sense and anti-sense probes as previously described (Ohnuma et al., 2002a).

Retinal cryosections were prepared as described previously. In situ hybridization with sense and anti-sense probes was performed following the basic steps followed in the whole mount hybridization with slight modifications. Briefly, sections were rehydrated in $1 \times$ MEM, fixed in MEMFA and washed in $2 \times$ SSC. Sections were treated in $10 \mu \mathrm{g} / \mathrm{ml}$ Proteinase $\mathrm{K}$ for $5 \mathrm{~min}$ at $37{ }^{\circ} \mathrm{C}$ and re-fixed in MEMFA Embryos were then washed in $2 \times$ SSC, treated with $0.1 \mathrm{M} \mathrm{TEA} /$ $0.25 \%$ acetic anhydride for $10 \mathrm{~min}$ and washed in $2 \times$ SSC. They were then treated with $50 \%$ ethanol for $1 \mathrm{~min}$ and then air-dried for $1 \mathrm{~h}$ in a laminar flow hood. Sections were pre-hybridized at $65{ }^{\circ} \mathrm{C}$ in hybridization buffer for $1 \mathrm{~h}$ and then DIG-labeled probes were added on the sections. Slides were glass covered, placed in a humidified tray and incubated overnight at $65^{\circ} \mathrm{C}$. Slides were washed in solutions of $4 \times$ SSC, $2 \times$ SSC and Rnase treated $(20 \mu \mathrm{g} / \mathrm{ml}$ Rnase A, $10 \mathrm{U} / \mathrm{ml}$ Rnase T1) at $37{ }^{\circ} \mathrm{C}$ for $30 \mathrm{~min} .10 \mathrm{~min}$ washes in $2 \times$ SSC, $1 \times$ SSC and $0.5 \times$ SSC were performed at RT, followed by one $30 \mathrm{~min}$ wash in $0.1 \times$ SSC at $55{ }^{\circ} \mathrm{C}$ and another at room temperature. Slides were incubated in blocking solution, $2 \%$ Boehringer Blocking Reagent, $5 \%$ goat serum in MAB (0.1 M maleic acid, $0.15 \mathrm{M} \mathrm{NaCl}, \mathrm{pH} 7.5$ ) for $30 \mathrm{~min}$. Antidigoxigenin-AP Fab fragment (Roche) was diluted 1:1000 in blocking solution and added on the slides overnight at $4{ }^{\circ} \mathrm{C}$. Slides were washed 4 times in $1 \times$ MAB for 10 min followed by equilibration in AP development buffer supplemented with $2 \mathrm{mM}$ levamisole for $1 \mathrm{~h}$ at room temperature. Color reaction is developed in BM Purple AP substrate (Roche) supplemented with $2 \mathrm{mM}$ levamisole until satisfactory signal had developed and then slides were washed in MEM and fixed in MEMFA. Slides were mounted in aqueous medium and covered with coverslips.

\section{Acknowledgment}

This work was supported by Fight for Sight PhD studentship (AB, UK), St Peters Trust (MK, SO), and Associazione Italiana per la Lotta al Neuroblastoma fellowship (AB, IT) and grant support by Regione Campania Lg. 5 (2008) (MZ), PRIN (MIUR) prot. 2008E5AZ5F_002 (MZ), FP7-Tumic HEALTH-F2-2008-201662 (MZ) and Associazione Italiana per la Ricerca sul Cancro (AIRC, 2009-2012) (MZ).

\section{Appendix A. Supplementary data}

Supplementary data to this article can be found online at http:// dx.doi.org/10.1016/j.gene.2012.08.001.

\section{References}

Aravind, L., Koonin, E.V., 1998. A novel family of predicted phosphoesterases includes Drosophila prune protein and bacterial RecJ exonuclease. Trends Biochem. Sci. 23, 17-19.

Beadle, G.W., Ephrussi, B., 1936. The differentiation of eye pigments in Drosophila as studied by transplantation. Genetics 21, 225-247.

Biggs, J., Tripoulas, N., Hersperger, E., Dearolf, C., Shearn, A., 1988. Analysis of the lethal interaction between the prune and killer of prune mutations of Drosophila. Genes Dev. 2, 1333-1343.

Bilitou, A., Watson, J., Gartner, A., Ohnuma, S., 2009. The NM23 family in development. Mol. Cell. Biochem. 329, 17-33.

Boyle, W.J., et al., 1991. Activation of protein kinase C decreases phosphorylation of c-Jun at sites that negatively regulate its DNA-binding activity. Cell 64, 573-584.

Carotenuto, P., et al., 2006. PRUNE and NM23-M1 expression in embryonic and adult mouse brain. J. Bioenerg. Biomembr. 38, 233-246.

Cepko, C.L., Austin, C.P., Yang, X., Alexiades, M., Ezzeddine, D., 1996. Cell fate determination in the vertebrate retina. Proc Natl Acad Sci U S A 93, 589-595.

Ciani, L., Salinas, P.C., 2005. WNTs in the vertebrate nervous system: from patterning to neuronal connectivity. Nat. Rev. Neurosci. 6, 351-362.

D'Angelo, A., et al., 2004. Prune cAMP phosphodiesterase binds nm23-H1 and promotes cancer metastasis. Cancer Cell 5, 137-149.
Daniels, M., Dhokia, V., Richard-Parpaillon, L., Ohnuma, S., 2004. Identification of Xenopus cyclin-dependent kinase inhibitors, p16Xic2 and p17Xic3. Gene 342, 41-47.

De Marco, N., Tussellino, M., Vitale, A., Campanella, C., 2011. Eukaryotic initiation factor 6 (eif6) overexpression affects eye development in Xenopus laevis. Differentiation 82 (2), 108-115 (Epub 2011 May 20).

Dyer, M.A., Cepko, C.L., 2001a. p27Kip1 and p57Kip2 regulate proliferation in distinct retinal progenitor cell populations. J. Neurosci. 21, 4259-4271.

Dyer, M.A., Cepko, C.L., 2001b. Regulating proliferation during retinal development. Nat. Rev. Neurosci. 2, 333-342.

Edlund, T., Jessell, T.M., 1999. Progression from extrinsic to intrinsic signaling in cell fate specification: a view from the nervous system. Cell 96, 211-224.

Garzia, L., Roma, C., Tata, N., Pagnozzi, D., Pucci, P., Zollo, M., 2006. H-prune-nm23-H1 protein complex and correlation to pathways in cancer metastasis. J. Bioenerg. Biomembr. $38,205-213$.

Garzia, L., et al., 2008. Phosphorylation of nm23-H1 by CKI induces its complex formation with h-prune and promotes cell motility. Oncogene 27, 1853-1864.

Hackstein, J.H., 1992. The lethal prune/killer-of-prune interaction of Drosophila causes a syndrome resembling human neurofibromatosis (NF1). Eur. J. Cell Biol. 58, 429-444.

Harland, R.M., 1991. In situ hybridization: an improved whole-mount method for Xenopus embryos. Methods Cell. Biol. 36, 685-695 (Department of Molecular and Cell Biology. University of California, Berkeley 94720, PMID:181116).

Harris, W.A., 1997. Cellular diversification in the vertebrate retina. Curr. Opin. Genet. Dev. 7, 651-658.

Holt, C.E., Garlick, N., Cornel, E., 1990. Lipofection of cDNAs in the embryonic vertebrate central nervous system. Neuron 4, 203-214.

Jablonski, M.M., Iannaccone, A., 2000. Targeted disruption of Muller cell metabolism induces photoreceptor dysmorphogenesis. Glia 32, 192-204.

Kim, S.Y., Ferrell Jr., J.E., Chae, S.K., Lee, K.J., 2000. Inhibition of progesterone-induced Xenopus oocyte maturation by Nm23. Cell Growth Differ. 11, 485-490.

Kobayashi, T., et al., 2006. Glycogen synthase kinase 3 and h-prune regulate cell migration by modulating focal adhesions. Mol. Cell. Biol. 26, 898-911.

Middelhaufe, S., Garzia, L., Ohndorf, U.M., Kachholz, B., Zollo, M., Steegborn, C., 2007. Domain mapping on the human metastasis regulator protein h-prune reveals a C-terminal dimerization domain. Biochem. J. 407, 199-205.

Mochizuki, T., Bilitou, A., Waters, C.T., Hussain, K., Zollo, M., Ohnuma, S., 2009. Xenopus NM23-X4 regulates retinal gliogenesis through interaction with p27Xic1. Neural Dev. 4,1 .

Nieuwkoop, P.D., Faber, J., 1967. Normal Table of Xenopus laevis (Dundin). North Holland Publishing Co, Amsterdam.

Ohnuma, S., Harris, W.A., 2003. Neurogenesis and the cell cycle. Neuron 40, 199-208.

Ohnuma, S., Philpott, A., Wang, K., Holt, C.E., Harris, W.A., 1999. p27Xic1, a Cdk inhibitor, promotes the determination of glial cells in Xenopus retina. Cell 99, 499-510.

Ohnuma, S., Hopper, S., Wang, K.C., Philpott, A., Harris, W.A., 2002a. Co-ordinating retinal histogenesis: early cell cycle exit enhances early cell fate determination in the Xenopus retina. Development 129, 2435-2446.

Ohnuma, S., Mann, F., Boy, S., Perron, M., Harris, W.A., 2002b. Lipofection strategy for the study of Xenopus retinal development. Methods 28, 411-419.

Orevi, N., Falk, R., 1974. The lethal interaction between the genes prune (pn) and killer of prune (Kpn) in Drosophila melanogaster. Arch. Genet. (Zur) 47, 172-183.

Orevi, N., Falk, R., 1975. Temperature-sensitive prune (pn) mutations of Drosophila melanogaster. Mutat. Res. 33, 193-200.

Ouatas, T., Abdallah, B., Gasmi, L., Bourdais, J., Postel, E., Mazabraud, A., 1997. Three different genes encode NM23/nucleoside diphosphate kinases in Xenopus laevis. Gene $194,215-225$.

Ouatas, T., Selo, M., Sadji, Z., Hourdry, J., Denis, H., Mazabraud, A., 1998. Differential expression of nucleoside diphosphate kinases (NDPK/NM23) during Xenopus early development. Int. J. Dev. Biol. 42, 43-52.

Perron, M., Kanekar, S., Vetter, M.L., Harris, W.A., 1998. The genetic sequence of retinal development in the ciliary margin of the Xenopus eye. Dev. Biol. 199, 185-200.

Rosengard, A.M., et al., 1989. Reduced Nm23/Awd protein in tumour metastasis and aberrant Drosophila development. Nature 342, 177-180.

Steeg, P.S., Bevilacqua, G., Pozzatti, R., Liotta, L.A., Sobel, M.E., 1988. Altered expression of NM23, a gene associated with low tumor metastatic potential, during adenovirus 2 Ela inhibition of experimental metastasis. Cancer Res. 48, 6550-6554.

Sturtevant, A.H., 1956. A highly specific complementary lethal system in Drosophila melanogaster. Genetics 41, 118-123.

Teng, D.H., Bender, L.B., Engele, C.M., Tsubota, S., Venkatesh, T., 1991. Isolation and characterization of the prune locus of Drosophila melanogaster. Genetics 128, 373-380.

Timmons, L., Shearn, A., 1996. Germline transformation using a prune cDNA rescues prune/killer of prune lethality and the prune eye color phenotype in Drosophila. Genetics 144, 1589-1600.

Timmons, L., Shearn, A., 2000. Role of AWD/nucleoside diphosphate kinase in Drosophila development. J. Bioenerg. Biomembr. 32, 293-300.

Timmons, L., Xu, J., Hersperger, G., Deng, X.F., Shearn, A., 1995. Point mutations in awdKpn which revert the prune/killer of prune lethal interaction affect conserved residues that are involved in nucleoside diphosphate kinase substrate binding and catalysis. J. Biol. Chem. 270, 23021-23030.

Zuber, M.E., Perron, M., Philpott, A., Bang, A., Harris, W.A., 1999. Giant eyes in Xenopus laevis by overexpression of XOptx2. Cell 98, 341-352. 